\title{
Tumor seeding along the needle track after percutaneous lung biopsy
}

Leonardo Guedes Moreira Valle', Rafael Dahmer Rocha', Guilherme Falleiros Mendes ${ }^{1}$, José Ernesto Succi², Juliano Ribeiro de Andrade ${ }^{1}$
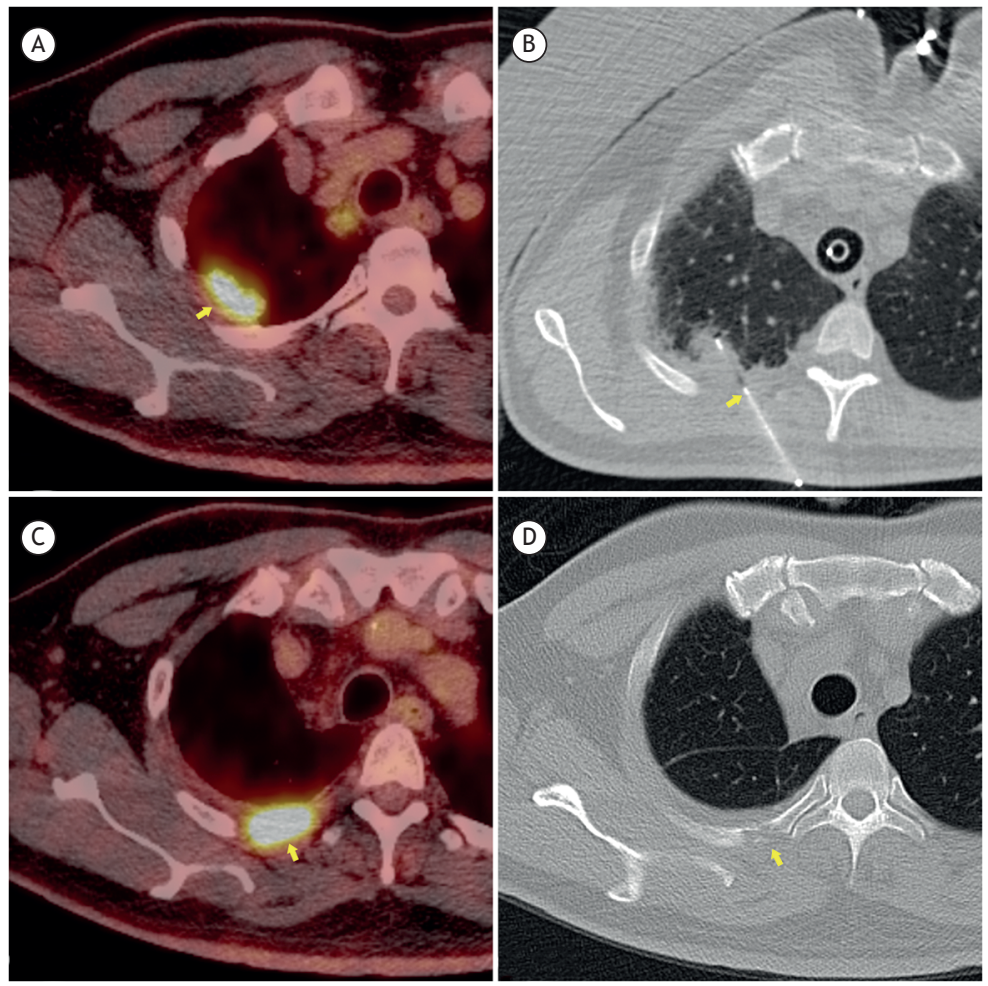

Figure 1. Nodule in the right lung apex and percutaneous biopsy of the same: in $A$, positron emission tomography-CT (PET-CT) scan showing the nodule (arrow); in B, CT scan showing the point of insertion of the coaxial needle (arrow); in C, PET-CT scan after 6 months of follow-up, showing an ${ }^{18}$ F-fluorodeoxyglucose-avid soft tissue mass; and in D, CT scan after 6 months of follow-up, showing bone erosion of the right third rib posteriorly (arrow).

A 56-year-old male patient underwent percutaneous biopsy of a nodule in the right lung apex (Figure $1 \mathrm{~A}$ ). The tip of a 19-gauge coaxial needle was positioned in the posterior chest wall (Figure 1B), and six samples of the lesion were obtained with a 20 -gauge core needle. The pathological analysis revealed squamous cell carcinoma. Using an anterior approach, we performed right upper lobectomy with tumor-free margins. At 6 months of follow-up, a positron emission tomography-CT scan of the chest showed an ${ }^{18} \mathrm{~F}$ - fluorodeoxyglucose-avid soft tissue mass (Figure $1 \mathrm{C}$ ) in the T3-4 interspace, along the biopsy tract, as well as bone erosion of the right third rib posteriorly (Figure 1D), suggesting tumor seeding. A subsequent CT scan of the chest, obtained two months later, confirmed local disease progression. We then performed en bloc resection with disease-free pleural margins, and the pathological analysis confirmed that tumor seeding had occurred.

Tumor seeding along the biopsy route is exceedingly rare. Certain factors, such as the use of large-bore cutting needles, increase the risk of such tumor cell dissemination, that risk also being greater when the tumor is an adenocarcinoma.

\section{RECOMMENDED READING}

Kim JH, Kim YT, Lim HK, Kim YH, Sung SW. Management for chest wall implantation of non-small cell lung cancer after fine-needle aspiration biopsy; Eur J Cardiothorac Surg. 2003;23(5):828-32. http://dx.doi. org/10.1016/S1010-7940(03)00095-2 